\title{
LA HERIDA DE LO AMBIGUO
}

\author{
Javier Bello* \\ Universidad de Chile \\ jbello@gmail.com
}

Se ha afirmado el carácter sobrecargado u oscuro de la escritura de Javier Bello y ha sido éste, inmediatamente, el primero en decir que tal oscuridad no tiene su origen (ni termina) en lo barroco, sino que impone relaciones y relecturas desde el romanticismo, el modernismo, el surrealismo, hasta la poesía actual. Ante el espectáculo y despliegue de tal escritura alusiva, confusa, sobreabundante, cierta crítica la consideró hermética, formalista, conservadora, etc., olvidando o soslayando que, ya para Sarduy, el barroco en cuanto exceso implicaba un arte revolucionario, frente al pensamiento económico (o el orden del discurso) burgués, o que para Perlongher lo neobarroco era un ejercicio de identidad y contracultura, que hacía de la escritura una piel tajeada, resistente en su tensión. A propósito de la sobreabundancia y de lo que no teme llamar "enunciación disidente" en la poesía de Javier Bello, el poeta Pedro Montealegre afirma: "El silencio, de acuerdo a esto, sería una potente forma de abundancia, lo mismo que el blanco: un referente político que define desde antes lo literario, aunque lo literario en sí evite su mención. No hay nada que se llene para que desborde, sino que esa aparente abundancia, ese instalarse en lo (des)conocido, trasunta el pulso vindicativo de lo negado; lo abundante,

JAVIER Bello (Concepción, 1972). Licenciado en Literatura Hispánica por la Universidad de Chile y egresado del Doctorado de Literatura Española Moderna y Contemporánea de la Universidad Complutense de Madrid. Autor de la edición crítica de la obra de Winétt de Rokha, así como de trabajos sobre sus compañeros de generación, antologías, encuentros de poesía, talleres (entre ellos, el taller de reescrituras del Canto General, donde participó como guía, fruto del cual se publicó la antología Desencanto personal), etc. Ha publicado $L a$ noche venenosa (Concepción: Letra Nueva, 1987); La huella del olvido (Concepción: Letra Nueva, 1989); La rosa del mundo (Santiago: Lom, 1996); Las jaulas (Madrid: Visor, 1998); El fulgor del vacio (Santiago: Cuarto Propio, 2002), que compila los dos libros anteriores más Los pobladores del entresueño; letrero de albergue (Huelva: Colección de poesía Juan Ramón Jiménez-Diputación prov. de Huelva, 2006); Espejismo (Santiago: Cuadro de Tiza, 2010) y Estación noche (Santiago: Calabaza del diablo, 2012). Los siguientes poemas han sido recogidos por su autor, como muestra de una poética personal y forman parte de su próximo libro, Los grandes relatos. 
entonces, sería lo no dicho, lo acallado, lo molesto, lo abyecto, que es lo mismo que decir lo asesinado, lo que no se puede nombrar, lo que no puede representarse en el escenario. Hablamos de una escritura que se instala sobre lo ya abundante, como la sombra del blanco. La escritura de Bello deviene la sombra del blanco". Evitar la vía de cierta poesía "contenidista", sin dejar de ser una poesía situada al decir de Lihn, donde el horror y el cuestionamiento de una escritura frente al aparato represivo se expresa mediante un lenguaje oscuro y difícil, constituyéndose, anfibológicamente, en un texto de goce en términos barthesianos y en una ambigua erótica de la herida y de la sombra.

\section{LA HERIDA DE LO AMBIGUO}

\section{EL CASO DEL REFLEJO}

Los días entrecruzados sobre ropajes que mienten, de cuento las garras del asno, las pezuñas del alfil, acusan a veces un brillo, babean las más de las veces la retórica fría del acantilado, su adherida destreza a tu signo, Lysi, que gira como una rueda quebrantando dentro de otra el oro de mis tormentos, los dientes de la turba enhiesta, la fábula negra de las tablas escritas por ambos lados, como melenas llorosas, como madera o un alma que en el agua se triza, sí, aunque no lo creas las voces, los buenos días, los días perdidos, los labios abandonados, las cartas que doy vuelta, se revuelcan al calor de los disfraces, en sentido contrario los labios, las lavanderas, la lengua entre las uñas, la lengüeta restriegan mi amor, lo enjuagan, lo abanderan, le dicen cuidado con la cabeza, la lluvia siempre fracasa, la lluvia no es ninguna, no te creas, sobre un campo de cielos consternados lame la grasa de los prematuros, las bocas del desdentado, la lluvia toma conocimiento del caso del reflejo, la cuerda deja temblando lo que deja, sopla sobre la ceja con ganas de prolongar los silbidos entre los aparejos, la monja impropia moja los cuadernos, firma el hueso como si fuera su hijo, ¿qué otra cosa podría suceder? ¿están todos los melancólicos en casa?

\section{ZOZOBRA DEL ABANDERADO}

Cuando el ojo se desenfunda y somete las barbas de kril, yo recuerdo a mi madre aunque esté contigo, en medio de las cosas, en la oreja no siento otro soplo que el miedo, otra luz que la tierra mojada, los surcos de pan tragándose el cangrejo, mis pies enlazados y torcidos, 
la raíz de la joya, el beso sin verdad, esta trenza en la trampa

del vidrio que camina sobre sus cuatro patas,

guarecido ya de espejos, de roperos, ya de festejos con lanzas

el abanderado se aleja en el sillón, el énfasis lo mima detrás del oleaje,

recién olvidado le pregunta qué sonido hay en su carne, qué preguntas en su olor

de grandes de Castilla, la ceniza más fina se convierte en flor de herrajes

y arroja por la espalda la pocilga. Cuando el ojo cansado de oropel

pregunta por mis huellas y se calla, cuando se acerca indecorosa

al cerebro intemperante la madeja, este hato de las jotas quiebra el hacha.

\section{LA PUERTA DE LA ESCAMA}

¿Qué quiere decir con eso de las jotas que se afilan en el lecho?

Eso quiere decir, ¿no estás de acuerdo? Un límite parece traer a la memoria

el peso de los sacos, acompasadamente lejos. Te hablo de la piedra que nunca estuvo sola, te escucho en la ceniza volcada. Los sacos traen seda, traen nada, traen lo que dejan, lo que arrastran, al borde de la aguja y del agua abandonan su vestido de llagas, dibujan en mi mano el rostro enmohecido, lo adivinan, lo auscultan como a negras señales. Recibo sus guarismos, los exhibo, las costuras se enfilan igual que sentimientos encontrados, los engendros se llaman, se encuentran, date cuenta, en la caja hay más preguntas que animales, doblan el paso sobre cuellos marchitos, los silbidos insisten como vena cortada, como cepos calientes en las canchas, chorros ecuménicos, estrábicos, el índice del fuego apuntando a las vestales con toda su madeja invertebrada, el adulterio de la rueda, el trance líquido, la flema de los sacos, las punzadas. Ay dime sin abrir los ojos cuántas veces llamaste a la puerta de la escama.

¿Qué quiere decir con eso del retrato? Lo mismo que padece, muchas gracias.

\section{HIJA DE LO INFORME}

Se había exhibido con destreza a un mismo tormento del alma

lo entredicho. Que el alma cuando se opone roza los emblemas, hincha el vacío olvidado en el cuerpo para ser lo entredicho. Ser a este lado del no ser

la sustancia que cuando cae a la loza se impregna, al paso sorprendido salmodia y lo convence de tenerlo vivo frente a sí, sin decir nada más y sin oírlo. Así sabe que Castilla se encuentra apercibida por visiones que permiten los visillos moriscos entre las casas altas. Y las cofradías andan con antorchas por el poco orden de las alumbradas, que son deformes igual frente a una cruz de palo como bajo el paño de los devotos que casan a su hija con la Ley, la resucitan aún después del miedo y sus colgajos siempre a puertas cerradas. De la hoguera no se vuelve, hermana, andan buscando frailecillos tiznados entre los guijarros y mujeres. Sobre todo en el vientre dicen que hay ramas nuevas, efigies en la entraña, que las cuerdas desfiguran como si fueran lanza o leño con gusanos. No seas arrogante, pero sé valiente, no quieras dar razón al engranaje, trágate la llave antes que caiga en las manos solteras de la nieve. Se había exhibido sin querer una gran madre levitando dormida contra las ventanas, el ojo en lo entredicho la objetaba, el tiempo la miraba sudando entre alacenas un orden que lo impío contorneaba 
como si fuera hija de lo informe. Que no puedan morir, que estén holgados al lado del susurro que los tienta y en la carne convence con soltura que este lienzo es mortaja del que muda, que esta llama cortante silba a solas su heredad extendida frente al fuego. Dime, Teresa, ¿qué goteras te alzan?

\section{PIEDRA DE BABEL}

...había que recorrer una gran desolación antes de llegar a algunas claridades José Lezama Lima

Goteras, silbidos, tetillas del Mar Muerto, gestos en la vía dolorosa cuando los olfatos quedan clausurados, se vienen abajo, enmudecen los conductos, los esfínteres, narices contrastivas, vacías como estopa en los predios marítimos, entre cuerpo y Dios ojos cerrados.

Puede desembocar en la mano una represa, la impaciencia de los canales desnudos ante el apuro de las corrientes desvestidas. Me veo en esos labios perdidos, en esas densas melenas que suspiran el nombre ardiente que en su decir olvida y en su silencio se alza.

Allí la lengua araña madreselvas, los insectos se nublan ante el torniquete, los deseos no escatiman la distancia viva. Allí, entre nubes y estertores, la cánula de los caminos tiene una cita con la tibieza.

Pongo los labios en el filoso apego que roe la coma del contacto y la cortina que se borra poco a poco para dejar aparecer el rostro que viene a hablarme como si fuera mío, en la hora final criado de la luna, agua fugaz donde el cristal restriega su paraíso de insensato sueño, los labios de la caja en que el esposo escupe despojado un crepúsculo cayendo sobe la rodilla nueva de su pensamiento. Miro la pared, la mancha de aceite, las resinas, me veo en esa hoja que ahoga la sangre en su color de cosa mezclada. Los olfatos se encapuchan, se aleja el desolado, el aduanero se cubre de aristas como un perro viejo, se cubre de huellas como un viejo camastro de ruedas y caballos. Piedra de Babel, sabe lo que escribe, y lo que no le salta al paso, le cierra el libro, le nubla las gafas, eclipsa la fisura en que la novia describe su cara al espejismo, en la boca de Lysi cortapisas mascándose a sí mismas, mordisqueando los labios timadores del trueque. Mal día para enterrar anzuelos, tengo que arder en un país de sombras dice Zenea cuando se queda solo y pule su casa entre dos arenales. Mal día para ser invitado, los olfatos se quiebran, los gestos repiten la nariz bajo el agua, el poeta camina al paredón, los lagartos se arrastran por el alfabeto sin sacar ni siquiera la lengua, la novia se tuerce atada al ouroboros, labios adoptivos del último muro del Templo. 
PLACENTA DEL RETRATO

y quedemos atados

como la heredera en el vientre de su madre

W. H. Auden

Las cosas son una en la confesión de mi madre y solamente en ella

encuentran un rumor que las toma del pelo y las aclara, pero aún ante su brillo puede desdecirse para llover sobre los toldos de la fascinante mascarada, de paso convencerme que lo que queda del vacío es una muesca, caer en su interior igual que un grito que se desfleca poco a poco y se dilata, examinarla desde todos los balcones como se hace con un exceso o con un auto de fe en Valencia, contemplar cada ojo apercibido desde el otro corral obliga la intervención de fuerzas invisibles, la placenta del pensamiento se enrosca sobre las trenzas de algo donde me voy hundiendo, a solas, Lysi, entre tus huesos transparentado al fin como el amor del mástil imprevisto, el súbito tormento del barco que se aleja desde ambos costados a la vez y es dulce en el regusto, tan adentro, al encender las velas del último sábado que pende del canal y no guarece, desvestirme allí en la hondura de pensamiento y objeción, de obra y lozanía, abandonar esas palabras en el buche donde el retrato se enternece, se amilana, como las alas enclaustradas tras el lecho de piedra o la oreja en las zarzas o la rubia pezuña del cerdo, un aerolito de estupor depositado contra el friso, contra el fuego, que se asemeja a lo que fue pero lo hace como carne sin fin, como delito levitando en las alcobas del reverso.

Las cosas se penetran, Lysi, hasta tu entraña, igual que el rey que viene a conocerlas, y al mirarse caer no se lamentan, triscan entre sus dedos, quedan resucitadas como venado al sol de los reflejos, como el pie que en mi madre justo antes de todo amanecer en sangre se despeña, en vilo se despeña, en vilo, en sangre.

Mira a la muerte me dijiste, ¡mírala bien!, está tan sola, tengo que ir a acompañarla.

LANA

me acusas a deudas, a más rehenes

Alfredo Gangotena

Los nuestros se escondieron, vivirán, dijiste, hija de corderos.

El rumor se trenza frente al fuego, reluce el aguacero en las cartas echadas, la prohibición de tocar adormece el objeto a distancia, párpado desigual abre en el muro figura enmascarada, abre el ojo clemátide, impar testigo, imagen desbordada para el cuerpo que pesa entre las onzas del regreso, vaga sin semilla, sin nombre entre las astas espejos ovan bajo el doble del arnés, pregunta por ti cuanto disuena.

Dijiste temerás, altar sin criatura, volverás a la casa desollada, al idioma del torno, al código poroso de la bienvenida. Es cierto lo que reza en su aposento el ácaro, es cierto, párroco del plancton, el óxido que engasta bajo el nido el nudo. Lo dice el humo, el pez, el exceso del galgo de la fe, el síndrome disperso de la arruga. Lo repite la piel en su tendal sobre las cosas, instrumento del cuero y de la lana, cascabeles que al símbolo retornan, irrumpen comunales, proliferan en el cuello falsos rojos, celestes bárbaros, territorios de implacable destreza. 
Parece una quemadura que se despereza, parece un silo, un sol, así sucede al centro del pan aparecido, el sexo del enjambre siempre al centro.

Bajarán hasta el valle, tenderán en los oídos tripa que cebaban.

¡Habeas corpus!, corte de ademanes. ¡Habeas corpus!, límite del tiempo.

\section{MELAHIM}

Vienen con el viento que trae arena, los llaman cabeza de arena.

Están cubiertos de pelo, saltan y se posan, no se arrastran.

No tienen sangre, rabí, consta que crujen.

Me los comería aunque se lamieran a sí mismos.

Del labio inferior, de la ubre del cielo

viene esta gramínea de los pájaros,

patas de alcohol, mensaje su carta de tres dedos.

Confesiones y tórtolas, codornices y apremios ilegítimos,

lentejas para Pesaj en las huertas de Astorga,

columnas, mercaderes, langostas del templo

suben la escalera por la pierna coja de los corderos.

Brasa de arcángel, demasiado hollín para morder

la trenza de los rebaños. Demasiado el tendón, los animales de humo

donde se sientan a hablar los parientes con mi abuelo.

Me conformo con siete velitas, lloro

contra la pared sobre mi brazo derecho.

Como rosa entre espinas va el rey a sus cámaras,

hijas de Salomón, como yo, de extranjera.

\section{ENFERMEDAD A DOMICILIO}

Qué predica en su lecho mientras dice

dame la aguja predicando

para salir del paso, la verdad

se tiene en pie, durísima se escurre.

Debe trepar soltera, sepan, salta, la cur

la curvatura de su oído.

Sin tregua, tiene tanto que decir, seré escribiente a solas de su bando.

O libro alzado o prosa de la tierra, sutura del copista, espejo laxo

la víscera en la mano, la avaricia

de unos pocos remiendos tras el trazo

traza. Alguien canta en el fuego, es el fuego

que quiere quemar todas sus cartas.

La niña de Sus ojos, la judía

y su dedo hacia Dios, es lo escrito

mi madre con su válvula en la hoguera

del quirófano, apunta a todos lados.

Se arreglaba la falda, sacudió 
hija la cordillera de Los Andes.

Estaba viva, tenía corazón, de sus encantos

canta la eternidad, habla con la enfermera.

\section{ALBABETO BARUJ}

El santo y seña dice la voz que quiere amanecer, baruj le contesta al tendón de la noche en puntillas quiere amanecer, el imán tonsurado se come las uñas hace ruido con los dedos, esperando, esperando, los nudillos arrugan el último después al paso de la suela proscrita, brasa en el cinto, las hornillas humean, el pantano interroga al levadizo inasible, al halcón las sonrisas, el gendarme silba prisionero, canturrea de pie en la puerta del tifón, prevalece como trance que escarcea en sus despojos, baruj le dice, acaba de decir y el libro nada devuelve, lo deja silbando y con su queja deja de hablar, la orquesta desordena deslenguados papeles, los instrumentos se deslíen tras su horizonte cabizbajo, tras la coronación sábanas altas, campanadas en una noche negra, se puede oír la sed, la pregunta gotea en su orificio, quiere amanecer, deja los instrumentos tras su dura pupila, baruj le contesta al perdulario, el enjambre votivo hojea el cuero, papel biblia, reina valera entre perlas de talco, jardines de babilonia, serafines incrustan dientes en tobillos con escamas, después de los suplicios la lengua se debate titubea en el pecho tricornio enjaezado, lo denuncia el santo y seña, la devoción granate de la sangre sin bosque, el armisticio inunda tras el cristal la noria, el alfabeto escampa apenas saboreado, quiere amanecer, baruj le dice, espinosa avemaría.

\section{EL PAN DE CARAVAGGIO}

El fondo para la cabeza de Medusa tiene que ser verde, verde también la carne donde el príncipe sufre y el cardenal deserta. Como cebo absorbido por la nítida niebla lo ambiguo se descompone igual que un objeto en el paraíso de los labios trenzados por espinas que obedecen a la mano tras los árboles. Había un ruido junto al cuerpo, un aleteo en los pasillos sin velo. Había un gran teatro saludando sobre la colina con el hambre de un pie que se baña. Había el breve olfato de la miel en el cuchillo que refleja la luna. Una lente convexa enfoca la sangre casi negra sobre el mármol triturado de los besos. Un biombo recubierto por las hojas del pubis donde el último descendiente de Heráclito juega a las cartas y sopla desmantelando el cielo de las estrellas fijas. El nieto de Tiziano y los cazadores de alfombras abierto en el césped con la uña de los camaradas del Este. Como la novia en la arcilla deletrea a los dioses mordisqueados por los pigmentos. Habrá tiempo indican los prosélitos para mirar el orden de los planetas sepultados bajo el cuenco de plata.

Por el rabillo del ojo la muerte de un muchacho mordido por un lagarto en las afueras de la ciudad del alma sin ombligo. El cadáver del comisario que flota boca abajo en el Tíber y el diente de la prostituta saludan a la marea entre los debutantes del carnaval de hilo. Seguido de lo cual en los mendrugos de pan sobre la mesa abren sus ojos manieristas los gusanos de la primavera. 


\section{LADRIDO PARA GOYA}

Sin naturaleza no se puede saber por qué la grande hazaña como espejo con cadáveres ya es otra cosa alguien podría argumentar que no cuando el garrote aprieta el niño está de chanza es parte de la risa se reparte en los campos con los calzones abajo colgado del tarot por leer el pliego en una reunión de hombres la cabeza separada del cuerpo en una rama los brazos en otra el caporal chasquea dedos muertos las mujeres dan razón los niños trabajan en una zanja con los intestinos de las abuelas el ojo clavado al picaporte el seso al teatrillo de la razón aquí en la plaza hiede otra leyenda negra.

\section{PASTOR DEL MAR}

Estos dedos que de dedos sólo tienen algunos vestigios de lluvia Juan Larrea

Se llama Juan, se llama Jeremías, le tiene miedo al frío de las cosas hace el sortilegio de las aspas hasta que el viento borra lo que queda apenas mueca de molino para el augur que escupe sobre el alba toda su muerte, ojo de diamante, criaderos al sol recién paridos como vides eléctricas silban su fermento intempestivo, su primera catástrofe de este lado sin miedo de la luna, la anémona en su ley, el telón de las algas craquelan la noche y la desnudan, dibujan al pie del precipicio la estatua y su rigor insepulto, la pluma que pesa entre las dádivas como un trirreme en llamas tras las bodas del cielo, el pájaro en la boca insiste en perfumar los dioses cálidos, cocinar un cuenco lleno de suplicios incendiar un atado con mentiras piadosas, el nacimiento de las viejas aguas cuando el brazo quiere un poco de ternura, cuando el cachorro mama en el flequillo la felicidad del gotario, su cielo restringido, el incestuoso pálido hace sobre el mar el sortilegio, oye cada noche al desdichado, ningún otro barranco teme a su nombre de la misma manera, ese juego de manos, el eclipse dormido a sus espaldas como un fósil, ningún otro barranco, ningún otro algoritmo cayendo en las hornallas como un fuego sin madre.

\section{EPIDEMIA Y TRIZADURA}

Nacer como hubiera querido el cielo que naciera por segunda, por tercera vez llegar hasta la fábula entre las piernas la desaparición de la persona, alumbrar la covacha secreta, la cabeza volcánica, la hija dorada del enigma muge entre las aguas, se desviste, cuídate niño de su acero de su carta espigada donde cena una ansiosa nación en los espejos hervir los implementos, tremar con la tormenta que ha decapitado los enjambres aquel día los pezones sahumados, la asfixia votiva de la estatua las trenzas aceitadas por la ebriedad del mar, tirante cada cuerda siete veces nacer, grano de nadie, insolado como el ojo en las aspas 
hijo de las alfombras y el genio meloso del almizcle

Nacer como nacen las heridas, llenas de felicidad por la muerte

como nace el algodón suspendido entre manos que rezan

aquí donde no saben, aquí donde no tiemblan, una vez, otra vez, el sol, la trizadura

la sábana, el forado, se me echa a llorar la cosa entre los fieles

la cajita que dice guárdate amor mío de toda tibieza

obscena la hoja diminuta de los árboles se suicida como una epidemia.

\section{LOS ALTARES DE LA COSTURERA}

No cabe duda, no hay nada que hacer contra la muerte, los instrumentos le roban su esquirla, la distraen, le dan de comer joyas baratas.

La invitación del amor, la miel que abre los dedos, las líquidas alfombras que cubren el hígado por siempre, la mala ventura al infiltrarse en los besos, el peso de la herida, la humedad de la herida, la visita amniótica del Eros, oscuramente la delatan. Como un libro asustado, como un convidado de piedra, como el corazón donde leuda la elipse, el hígado pasa el invierno en la bóveda del artesano, atesora las rosas para la despedida, la imagen del tiempo que se despedaza ante la vigilia descrita por los instrumentos. Qué más le dan de comer, por favor no me digas, trenzas de laurel con miedo, encaje mordisqueado del otro lado del bosque, estrellas que repujan pasos imperiales, estigmas imperfectos, raciocinio.

La muerte reticente hace su ronda, impone allí sus términos, doblando las esquinas los muele, los mastica con cansancio mientras el hígado mancha las paredes como un siglo abigarrado de distancias que vienen del Mesías, latitudes permanentes que descienden tiritando de la bola de pelo. No cabe duda alguna, era Castilla, era en la fiebre la misma corona triturada sobre el cielo de las alpujarras, interrogada sin defecto por su propia maternidad reversible, la pobre tinaja anegándose encinta sobre los baldíos amoratados de la paloma. Aprovechemos de lamentarnos todos juntos ahora que estamos entre hermanos, aprovechemos de maullar la noche entera como si hubiésemos sido invitados. Ni una palabra más, sin duda alguna no es largo, aunque tampoco tan breve, el testimonio de los huesos quemados que cantan su vergüenza en los altares de la costurera. La invitación del amor, las escenas sin traje, el hígado acostado dentro de mi oreja.

GANCHO EN EL ESPEJO

bueno
estoy muerta
y quiero divertirme
S.T.

Esta tarde he pensado que la muerte se acerca tambaleándose como un gran cargamento de higos, de luces y aceitunas, ataviada con dientes e insectos que fríen agujas, fríen dedales, una ígnea función celebran los magos del esfuerzo para arder y calibrar la inclinación del pubis, el arnés en el frío sistema de invierno, fantasmas aceitados entre los disfraces con que enseña su saña la mandíbula, adornada de conchas y espejos, cloqueando en el pesebre de las tuberías, 
el magma pestañea fijo en ataúd sellado.

Lana para hilar fino trae el colchón de la muerte con su fruta mordida por los intensos párrocos, ventrílocua asusta en las esquinas del viento que despeina todo lo que dobla,

el carruaje con sus vendas sin tiempo, quién entonces sin tiempo

ayuda a pespuntear apenas las solapas, apenas las hechuras del numen,

quién el tejido que Thénon eviscera esta tarde en la vena proscrita de la bailarina,

el plancton que adora tu pelo, apenas tu manto de escamas,

apenas tu cepo sin gula. Yo escribo este poema condenado por la succión del musgo,

por la ascensión del vientre hacia la cima insurrecta.

Esta tarde he pensado que la muerte se acerca

con su largo volumen de incisivos maduros que caen de la ingle a la celda,

el cuerpo rojo, la joven quietísima será un recuerdo entre las fosas,

el rebaño que ahúma tu rito enmascarado en los espejos.

Me queda entre los dedos el vacío, cuanto he gobernado con fiebre,

en la salud la enfermedad del polen, la arruga musical resquebraja los mudos implementos,

la voz abre en la espina tu dolor tras el esófago,

un litro de dervichas masturbando el eje cuando giran en claustro.

Nupcial la muerte regurgita azumbre de señuelos lambiscones,

la multitud rendida al agasajo de no verte más que en sueños

donde muerden la alfombra, donde arañan, para alumbrar apenas contra el país secreto

el sol de los venenos, el grano de la ofrenda, la muerte apenas tambaleándose.

Susana entre espinas lo puede quizá decir de otra manera.

\section{EL MENSAJERO}

No son los diminutos silabarios de fuego detrás de los que viene el heraldo, el heraldo está muerto y fracciones de invierno lo toman de la mano para bajarle la fiebre antes que desaparezca del todo, conmovido por la persistencia de la erosión y los depósitos metálicos, arrastrado hasta lo infinitesimal de la sílaba por el carruaje de la unidad prestada. La verdad es que son dos, siempre son dos, de ahí la sed irreductible. Es él y su hermano, él y su novia de vidrio. Una sola trizadura los separa en el vientre, un mismo cortinaje de reflejos en que lo uno es uno y su primera versión el azogue sin nadie. Entre esto y aquello hay algo, entre algo y la nada otra cosa. Detrás de algunos números de sombra garúan los que se echaban de menos, al final del algoritmo aparecen los desaparecidos, la secuencia de las interrogaciones se hace infinita, la plataforma de las preguntas se vuelve insoportablemente pesada. Voces en estado sólido, voces en estado larvario, gente que vagaba por ahí y tuvieron hijos y no pudieron ponerse de acuerdo. Los que miran el mar dentro de un libro, los que cambiaron sus nombres, los que dejaron de rezar al Dios de los acorralados, los que cargan flores en los brazos mientras la dentadura negra de los cadáveres cojea por el barranco. El heraldo vuela alrededor del fuego como una mariposa nocturna con grandes ojos de estuario, las alas borroneadas por las yemas de las víctimas, el tablón al que no dejan de aferrarse. Carnadas verdes, verdes espejismos, manos cortadas naufragan en el río verde. Y el heraldo, hermana de la humedad y los colores, se santigua con el cráneo abierto. 


\section{EL ARTESONADO DE LA SINAGOGA}

No hay nada en el baúl de los muertos que no sea sospechoso de un pasado remoto. Las piernas del jardín se entreabren de derecha a izquierda como las cartas que aluden al alfabeto rizado. En el momento de deshacerse, la garganta salvaje duda si pronunciar la sed, la sílaba madre, la hoguera del último rey de los monos. Llena de prismas, la memoria reduce las posibilidades de acertar al color de la tribu, las desviaciones de la lengua vestidas en trajes de época juegan con sus genitales a la orilla del río. Como el silbo de Dios en las piedras del acantilado, las medias rasgadas suelen revivir el pulso de las festividades ajenas. Nada yace detrás de la lluvia que pueda repetir lo que dicen las cucharas donde falta la leche y la miel del reflejo. Ah las viejas postales y los daguerrotipos y las tarjetas de presentación y los cuadernos de croquis y los diarios de vida abandonados en los orfanatos, como la carne representan un flujo continuo. Como si se tratara de la mano que escribe, los dedos fantasmas y las páginas desatendidas por los copistas se acercan sin titubear a la frente, la manchan con tinta, con mosaicos en ruina, con humo de incendio, la arañan con todo lo que no es transparente. Entonces las letras se fugan, dejan el libro en la arena, sin mirar atrás seducen a la estaca del pantano con el ojo encubierto, convencen al rostro en la almohada, pierden el rostro, lo arrastran entre cortinajes en celo, entre la ropa que ha sido declarada muerta, comprenden por fin que no hay espejismo que valga en el fuego, que no hay exterminio que no traiga consigo la reunión de la escama, la ojiva bizca y el perro de los macabeos. Abismo y celosía, el artesonado de la sinagoga, el blanco que Severo tiñe con café y Sarduy con sangre.

\section{CUENTAGOTAS}

El cuentagotas sonríe ante la forma despiadada como si fuera un golpe de muerte sonríe del lado donde se cierra la madre que abre los ojos del revés

va y viene como la marea hasta que el imán rompe el vínculo

anuncia el eco de luces secuestradas, huestes en la crecida del río, el doble que me falta

el lazo entre los dedos anuda una tormenta de señales

asilados los párpados, las preguntas vienen sin ser invitadas, se muerden los codos

esas sangres piadosas, estos labios que cuelgan de las astas

noches amarradas al cuello escriben el sueño de los animales

las escamas, los árboles desconocidos, la tierra que se acuesta con nadie

entonces las tenazas se quedan con la piel, sonríen entonces

la regalan como un recuerdo envenenado, una muerte que abotona el traspié

el olfato me encubre, la mirada se ausenta ante el plagio de las puertas mal cerradas cruza el puente descalza, va y viene como la marea, el paraíso resbala

sobre la estopa seca, el sábado riza las sandalias, la cicatriz se muda a los espejos

figuras enlutadas, manchas en la pared, los ojos húmedos tras la polvareda

esta tibia borrasca, esa nieve ilusoria que procrean los árboles

velado el pie, ácimos los dedos, la marea va y viene, el traje se descalza

el perro de escombros devuelve la sonrisa a su hospedaje

la casa del sol llena de fantasmas, el mensaje sedicioso de mis actos, quizá

la única salida 
clenching your fist for the ones like us who are opressed by the figures of beauty Leonard Cohen

Puedo rastrear la voz tras la herida del paladar ambiguo

para trasquilar el disfraz en tu partidura sin corona, leporina a la sombra de viejas pestañas, enjaezada de rizos y espuma. Puedo besar la red de la quijada, tu hueso de jabón, la espina cuando el tejado llueve su porción de nombre, tu apuro en el hollejo, la cálida aversión sometida que se deja sentir como aceite en los vasos, como podrida azúcar en el huevo, el cascabel que lamen las cucharas, la resaca que filtran los nudillos afligidos como un traspié del mundo y de su glosa.

Podría rebanar mi atracción pero no puedo, yo no estoy mientras el niño retoza en la gasa de valva y de ballena, y todo lo que huele se adultera a través del puño sin resquicio, esa sutura atada por tu sexo que me deja mordisquear las algas tibias, enharinado el dedo, en santidad la uña, su halo débil que tirita, saliva en el solfeo, se estrangula con la cinta dentada.

Podría reparar el precipicio, pero el que amo en el hojaldre se despeina, hereda y regurgita entre las armas un dorado batallón de légamo, el manojo de huesos que nadie ha convertido en otro abismo, el muñón de la voz donde el pulpo recala como astuto reo sin tentáculo.

Así es, eso queda, la boca marsupial y tu pregunta sobre la confección de muecas, ese mueble indigesto con que el mundo se adorna y hace burla a todo lo acabado en qué, de qué, para que pueda rastrear la herida de lo ambiguo. 